\title{
Optimization of a reinforced concrete structure subjected to dynamic wind action
}

\author{
Jherbyson Williams Silva Brito \\ PPGEC/UFRGS, Braril \\ Jherbyson.willians@gmail.com, bttps://orcid.org/0000-0002-1481-1803 \\ Letícia Fleck Fadel Miguel \\ Department of Mechanical Engineering, Federal University of Rio Grande do Sul, Brazil \\ letfm@ufrgs.br, bttps:/ / orcid.org/0000-0001-9165-4306
}

\begin{abstract}
This work proposes a methodology to optimize a reinforced concrete structure. For this, the Whale Optimization Algorithm (WOA) algorithm was used, an algorithm from the group of metaheuristic algorithms, which presents an easy computational implementation. As a study object, a frame structure adapted from a real reinforced concrete building was used, subjected to the dynamic action of artificially generated synoptic wind. The objective function is to reduce the volume of concrete of the structure. For that, the dimensions of the cross-sections were used as design variables, and the maximum displacement at the top imposed by the ASCE / SEI 7-10 standard as a lateral constraint, as well as the maximum story drift between floors. In addition to this structural optimization, it was also proposed the use and optimization of Tuned Mass Dampers (TMD), in different quantities, positions and parameters, improving the dynamic response of the reinforced concrete building. The results show that for this situation it was possible to reduce the concrete volume of the structure by approximately $24 \%$, respecting the maximum limit of displacement at the top required by the standard.
\end{abstract}

KEYwORDS. Optimization; Concrete structure; Metaheuristic algorithms

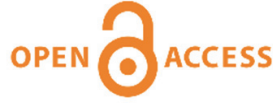

Citation: J. W. S. Brito and L. F. F. Miguel., Optimization of a reinforced concrete structure subjected to dynamic wind action, Frattura ed Integrità Strutturale, 59 (2022) 326-343.

Received: 27.09 .2021

Accepted: 09.11.2021

Published: 01.01.2022

Copyright: (C) 2022 This is an open access article under the terms of the CC-BY 4.0, which permits unrestricted use, distribution, and reproduction in any medium, provided the original author and source are credited.

\section{INTRODUCTION}

I $\mathrm{t}$ is notable that buildings are getting thinner, mainly due to technological innovations in relation to constructive solutions and quality of new materials. Previously low and robust constructions now make room for increasingly taller and more flexible structures, because of reduction in cross-sections due to the gain in strength of the new materials. In relation to the structural design of tall buildings, the dynamic effects due to the wind are important, because if the proper care is not taken in the design, excessive vibrations may arise, causing discomfort to residents and/or users and consequent economic losses, and in an extreme case, the structure collapses, as has already happened in several cases around the world. Due to constant development and the search for efficiency and competitiveness in cost and weight reduction in structural projects, optimization methods are increasingly being applied in search of the best project, in which applications in the 
aerospace areas, engineering projects are being increasingly applied, equipment, automotive, among other areas of engineering.

One of the first articles on optimization in tall buildings was that by [1], in which the authors describe the evolution of a group of optimization algorithms created by them, with the objective of optimizing the areas of the structural model bars, submitted a design maximum lateral constraint. Venanzi and Materazzi [2] performed a multi-objective optimization process of a communication tower for mobile devices subjected to turbulent wind loading.

Yang et al [3] analyzed the control of the dynamic response of a tall building using a tuned mass damper on the top of the structure. It is a Benchmark structure, an example used as a study reference by several authors.

Many classical or conventional algorithms for structural optimization are deterministic and most of them use gradient information, that is, they use function values and their derivatives. They usually work extremely well for smooth unimodal functions, however, if there is any discontinuity in the objective function, they may not converge [4].

Due to these difficulties, Heuristic and Metaheuristic algorithms have been increasingly used, which are based on randomization and local search from candidate populations, and not from a single point as happens with classical methods [5].

These algorithms are classified into four categories: evolution-based, physics-based, swarm-based, and human-behaviorbased. Some examples of algorithms are the Genetic Algorithm (GA) [6], which is an evolution-based algorithm, the physicsbased Gravitational Search Algorithm (GSA) [7] and the Harmony Search (HS) [8] based on human behavior.

Swarm-based optimization methods reproduce the social behavior of groups of living beings. Among the best-known algorithms for this method are Particle Swarm Optimization (PSO) [9] and Ant Colony Optimization [10]. In this paper will be used the Whale Optimization Algorithm (WOA) [11] developed by Mirjalili and Lewis.

Optimization algorithms can be used to optimize parameters, positions and quantities of passive energy dissipation devices, with the objective of reducing the dynamic response of the structure, respecting normative limit values. This is used to reduce the amplitude of oscillations caused by dynamic excitation in different types of structures. These systems aim to reduce the dynamic stresses that can occur in buildings, avoiding problems such as fatigue and ensuring structural safety. The purpose of structural control in civil engineering structures is to reduce vibrations produced by external forces such as winds and earthquakes, by different techniques such as modification of stiffness, mass, damping and geometric shape [12]. Vibration control systems can be divided into two main groups, active and passive systems. Passive control systems are devices composed of a mass connected to a spring and a damper to the structure, so that this device absorbs part of the energy from dynamic loading, dissipating the energy in the members of the structure. This system has advantages because it does not have the need for energy or control external to the structure, working by the vibration of the building itself, thus being of low cost compared to the active system, as well as installation, maintenance and ease of control. It's optimally tuned to protect the structure from dynamic load at a specified frequency. However, it's not efficient for other cases and other types of dynamic loads. This is one of the negative points in relation to active systems [13].

Active systems adjust to different vibration frequencies through sensors requiring information on structural behavior and external energy. This system is operated by hydraulic or electromechanical actuators that provide control forces to the structure from monitoring with sensors that measure excitation and/or response due to dynamic load [14].

A classic device widely studied by structural engineering researchers is the Tuned Mass Damper (TMD). It's an efficient mechanical device that features low cost and low maintenance. Furthermore, these devices can be installed, for example in a building, without interrupting the building's operational activities. Another advantage these attenuators have over other control devices is their versatility, as they can be designed in many different shapes and sizes, which facilitates adaptations to architectural aspects and space limitations [15].

Several researchers use this device, and prove the reduction of displacement peaks at the top of structures ([3],[16] and [17]). So, the main objective of the present work is to optimize the volume of a reinforced concrete structure according to maximum displacement restrictions established by international reference standards. For this, the optimization algorithm proposed by [11] is used. The cross-sections of the members are considered as design variables. After the optimization of the structure, TMD's are installed and optimized, in different quantities, positions and parameters.

\section{APPLICATION OF TMDS IN THE STRUCTURE}

$\mathrm{T}$ here are several TMD's design methods in the literature, among which the [18] and [19] can be highlighted, which are used for the design of simple TMD installed on top of the buildings studied. From these methods, the optimal values of stiffness, damping and tuning frequencies of the device can be found. However, in this paper these values 
will be obtained from the optimization process performed by the algorithm used, both for simulations with a single TMD at the top and for TMDs.

To analyze the response of the structure with a TMD on top, as shown in Fig. 1, it is necessary to make changes in the stiffness, mass and damping matrices, in order to take into account the Degree of Freedom (DOF) of TMD. In general, the matrices can be modified according to Eqns. 1,2 and 3, taking into account that the building is of the shear building type and only the horizontal DOF is considered, therefore, the global mass matrix is of the type diagonal, where the mass of each floor and each TMD occupies a position on the main diagonal.

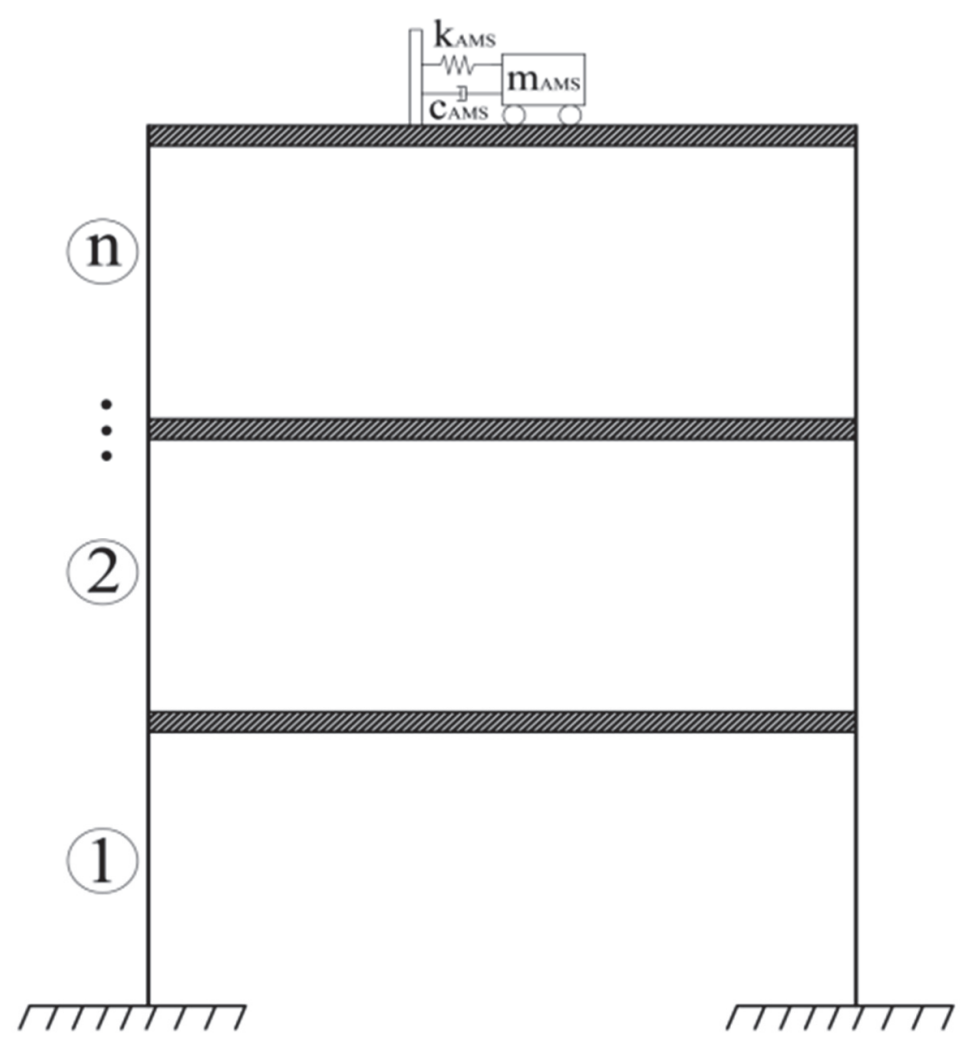

Figure 1: n-degree-of-freedom system (n-DOF) structure equipped with one TMD at the top floor

$\mathbf{M}=\left[\begin{array}{ccccc}m_{1} & 0 & \cdots & 0 & 0 \\ 0 & m_{2} & \cdots & 0 & 0 \\ \vdots & \vdots & \ddots & 0 & 0 \\ 0 & 0 & \cdots & m_{n} & 0 \\ 0 & 0 & \cdots & 0 & m_{T M D}\end{array}\right]$

$\mathbf{K}=\left[\begin{array}{ccccc}k_{1}+k_{2} & -k_{2} & \cdots & 0 & 0 \\ -k_{2} & k_{2}+k_{3} & \cdots & 0 & 0 \\ \vdots & \vdots & \ddots & 0 & 0 \\ 0 & 0 & \cdots & k_{n}+k_{T M D} & -k_{T M D} \\ 0 & 0 & \cdots & -k_{T M D} & k_{T M D}\end{array}\right]$ 


$$
\mathbf{C}=\left[\begin{array}{ccccc}
c_{1}+c_{2} & -c_{2} & \cdots & 0 & 0 \\
-c_{2} & c_{2}+c_{3} & \cdots & 0 & 0 \\
\vdots & \vdots & \ddots & 0 & 0 \\
0 & 0 & \cdots & c_{n}+c_{T M D} & -c_{T M D} \\
0 & 0 & \cdots & -c_{T M D} & c_{T M D}
\end{array}\right]
$$

In many cases, the use of a single TMD can be enough to solve the problems of excessive vibration of structures. However, for some situations, the use of only one TMD may not be efficient, as in the case of structures subjected to wind and earthquake, when more than one mode is excited. Another difficulty would be with the mass of the TMD being too large, requiring a very large space for installation.

In this sense, there is the possibility of using multiple TMD's (MTMD), each tuned to a specific frequency of the structure, thus being more efficient than a single TMD. While a single TMD is usually installed on top, MTMD can be installed in different positions and configurations, in series, in parallel, on a single floor or multiple floors.

In relation to the MTMD, they can be arranged horizontally, vertically, one per floor or several per floor, as shown in Fig. 2. Thus, for TMD's arranged horizontally and vertically in a building and in cases where the mass matrix is considered diagonal, the equation that indicates the modification of the matrix $\mathbf{M}$ is similar to the case of a single TMD, as already presented in Eqn. 1, and for the stiffness matrix, which is analogous to the damping matrix, we have Eqn. 4.

Some examples of the use of TMD in buildings are Citicorp Center, opened in 1977, in New York, USA. This was the first application of a TMD for wind response control, with the metallic structure being 279 meters high. The attenuator was built in concrete, weighing 400 tons and installed on top of the building.

The TMD mass is calculated from the mass ratio between the TMD and the structure. These values, according to researchers, can vary between 0.01 and 0.2 , that is, up to about $20 \%$ of the structure's mass. It is known that the greater the mass ratio between the TMD and the structure, the greater the TMD mass value. However, the value of the mass of the TMD is not interesting because it is a very high value, as it will add additional load to the structure under analysis, making it unfeasible due to the cost and difficulty of implementation.

Therefore, the optimization of the attenuator parameters becomes of fundamental importance, as well as their quantity and position. However, this problem is not so simple, requiring the use of optimization algorithms that are widespread in engineering problems. In this paper, the stiffness and damping parameters of each attenuator are obtained through structural optimization.

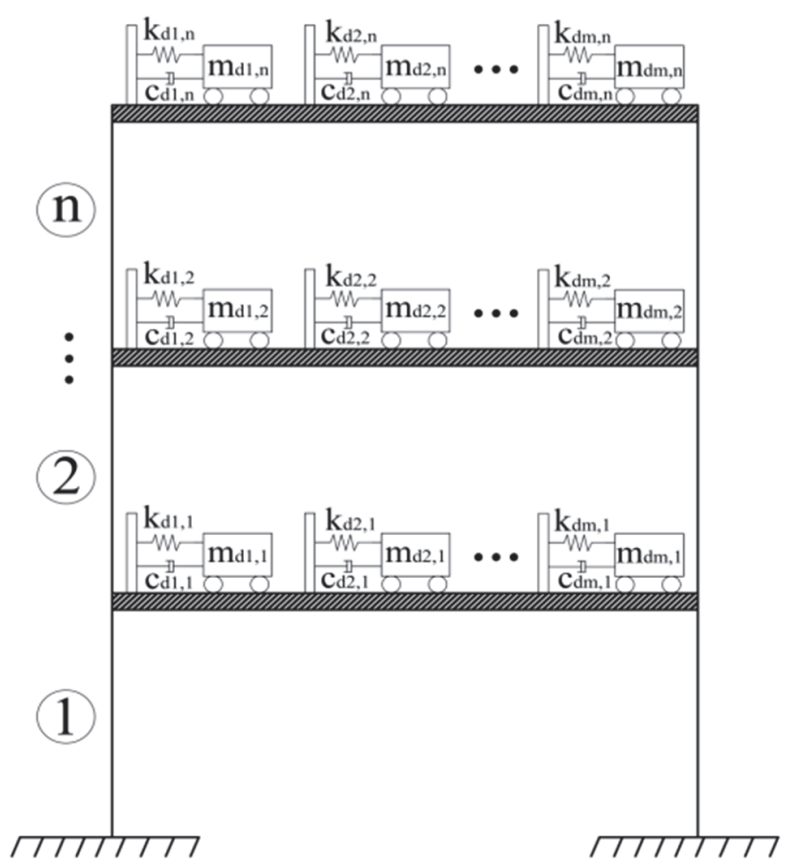

Figure 2: n-degree-of-freedom system (n-DOF) structure equipped with TMDs possibly located in all floors of the structure 


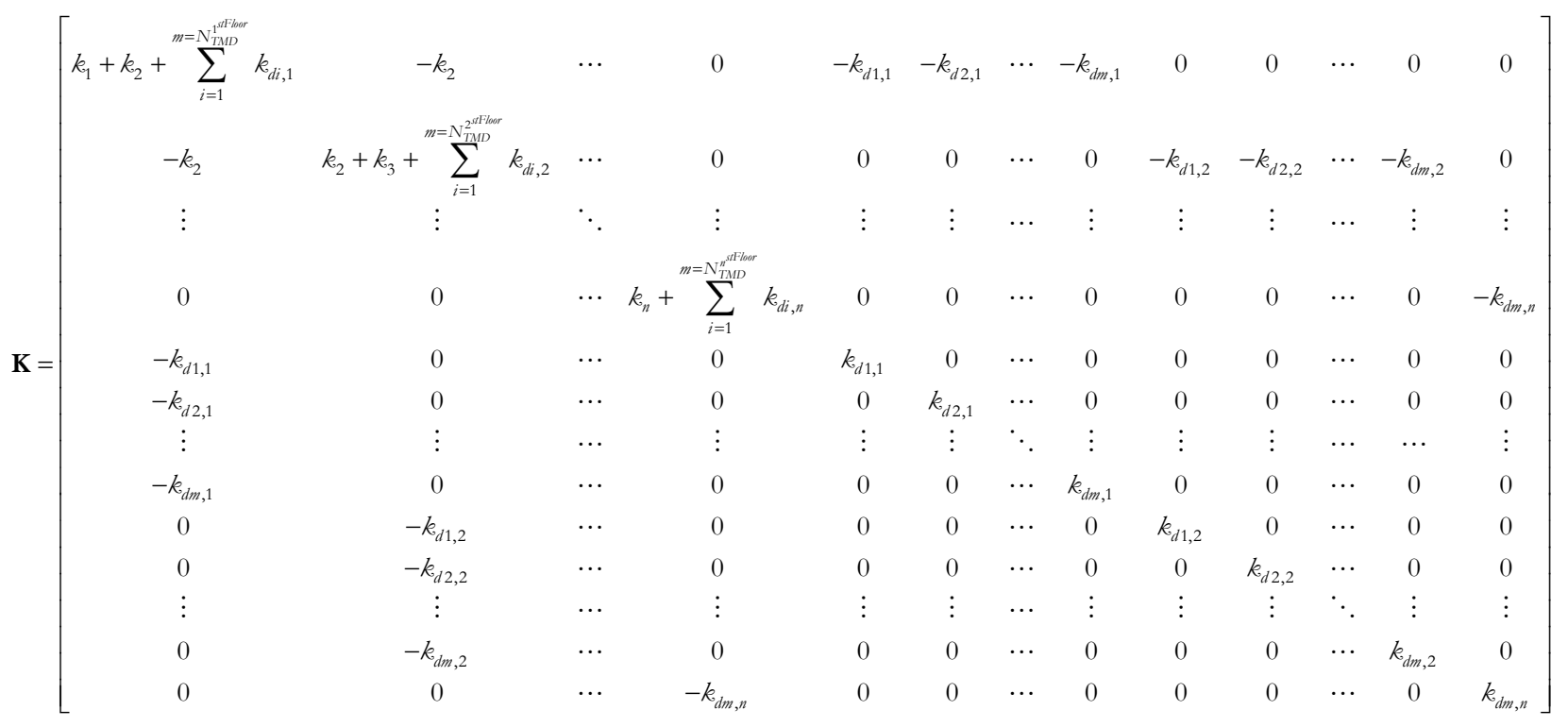

\section{Proposed METHOdology}

\section{Analyzed Structure}

he structural model is a 42-story reinforced concrete buildong, $\nu=0.2, p=2500 \mathrm{~kg} / \mathrm{m}^{3}$, and modulus of elasticity calculated in accordance with [20]. The total height of the structure is 105.38 meters, with 324 bars, modeled in Octave using the 2D frame element with 2 nodes and 3 degrees of freedom (DOFs) for each node. There are 185 nodes and therefore 555 DOFs. The sections of the bars are rectangular, with dimensions as explained in Tab. 1.

\begin{tabular}{cccc}
\hline Bars & Dimensions $(\mathrm{cm})$ & Areas $\left(\mathrm{m}^{2}\right)$ & Inertia Moment $\left(\mathrm{m}^{4}\right)$ \\
1 to $36 / 145$ to 180 & $100 \times 25$ & 0.25 & $1.30 \mathrm{e}-4$ \\
37 to $72 / 109$ to 144 & $25 \times 120$ & 0.30 & 0.036 \\
73 to 108 & $40 \times 157$ & 0.628 & 0.129 \\
181 to 324 & $12 \times 65$ & 0.078 & $2.75 \mathrm{e}-3$ \\
\hline
\end{tabular}

Table 1: Geometrical properties of the structure

The structure is shown in Fig. 3. The dimensions are in meters (m).

The Rayleigh Damping Matrix is used, where the critical damping ratio $(\zeta)$ was specified as $1 \%$ for the first two modes of vibration. The mass matrix of the structure is consistent where for each element, the mass and stiffness matrix in the local system, is represented by $\mathbf{M}_{\mathrm{L}}$ and $\mathbf{K}_{\mathrm{L}}$

$$
\mathbf{m}_{\mathbf{L}}=\frac{\rho A L}{420}\left[\begin{array}{cccccc}
140 & 0 & 0 & 70 & 0 & 0 \\
0 & 156 & 22 L & 0 & 54 & -13 L \\
0 & 22 L & 4 L^{2} & 0 & 13 L & -3 L \\
70 & 0 & 0 & 140 & 0 & 0 \\
0 & 54 & 13 L & 0 & 156 & -22 L \\
0 & -13 L & -3 L & 0 & -22 L & 4 L^{2}
\end{array}\right]
$$




$$
\mathbf{k}_{L}=\left[\begin{array}{cccccc}
\frac{E A}{L} & 0 & 0 & -\frac{E A}{L} & 0 & 0 \\
0 & \frac{12 E I}{L^{3}} & \frac{6 E I}{L^{2}} & 0 & -\frac{12 E I}{L^{3}} & \frac{6 E I}{L^{2}} \\
0 & \frac{6 E I}{L^{2}} & \frac{4 E I}{L} & 0 & -\frac{6 E I}{L^{2}} & \frac{2 E I}{L^{2}} \\
-\frac{E A}{L} & 0 & 0 & \frac{E A}{L} & 0 & 0 \\
0 & -\frac{12 E I}{L^{3}} & -\frac{6 E I}{L^{2}} & 0 & \frac{12 E I}{L^{3}} & -\frac{6 E I}{L^{2}} \\
0 & \frac{6 E I}{L^{2}} & \frac{2 E I}{L^{2}} & 0 & -\frac{6 E I}{L^{2}} & \frac{4 E I}{L}
\end{array}\right]
$$

A code was developed to calculate the natural frequencies of the structure, and later it was compared with the commercial software Ansys Mechanical APDL. The results of the first 3 natural frequencies are shown in Tab. 2:

\begin{tabular}{cccc}
\hline Vibration Mode & Octave Frequency $(\mathrm{Hz})$ & Ansys Frequency $(\mathrm{Hz})$ & Error $(\%)$ \\
1 & 0.3989 & 0.3989 & 0 \\
2 & 1.2829 & 1.2829 & 0 \\
3 & 2.3999 & 2.3994 & 0.03 \\
\hline
\end{tabular}

Table 2: Comparison between natural frequencies

\section{Wind Excitation}

For the generation of the synoptic wind, the wind action is considered as a stochastic process, that is, defined through an unlimited sequence of random variables. The fluctuating component of the wind is given through atmospheric turbulence, considering only the effect of the kinetic energy of the gusts, disregarding the neighborhood effects.

According to the [21], the component of the global wind force, called drag force, is calculated according to Eqn. 7:

$$
F=0.613 C_{a} A_{z} V^{2}
$$

where $C_{a}$ is the drag coefficient of the structure, $A_{z}$ is the area of application of the dynamic wind pressure, in $\mathrm{m}^{2}$ and $\mathrm{V}$ is the wind speed component. The drag coefficient is a function of the building geometry and the wind turbulence level, using the coefficients in Fig. 4 from [21] for low turbulence winds and Fig. 5 for high turbulence winds.

The longitudinal direction is the only one that contains significant mean velocities, being considered the predominant direction. The characteristic wind velocity is given by the sum of the static and dynamic plots, can be written as Eqn. 8:

$$
V_{x}(t)=\bar{V}+v_{x}(t)
$$

where $\bar{V}$ is the component of the mean velocity in the longitudinal direction of the wind, $v_{x}(t)$ is the floating portion of the velocity in longitudinal direction. Initially, the design speed is defined through Eqn. 9, which corresponds to the average speed in a 10-minute interval at a height of 10 meters from the ground:

$$
\overline{V_{P}}=0.69 V_{0} S_{1} S_{2} S_{3}
$$

where $V_{0}$ is the basic reference wind speed where the structure is located, of a $3 \mathrm{~s}$ gust, exceeded on average once in 50 years, at $10 \mathrm{~m}$ above ground, in flat open ground. $V_{0}$ must be adequate to the location of the construction, and can be obtained by the isopleths of the basic wind speed of the [21]. 


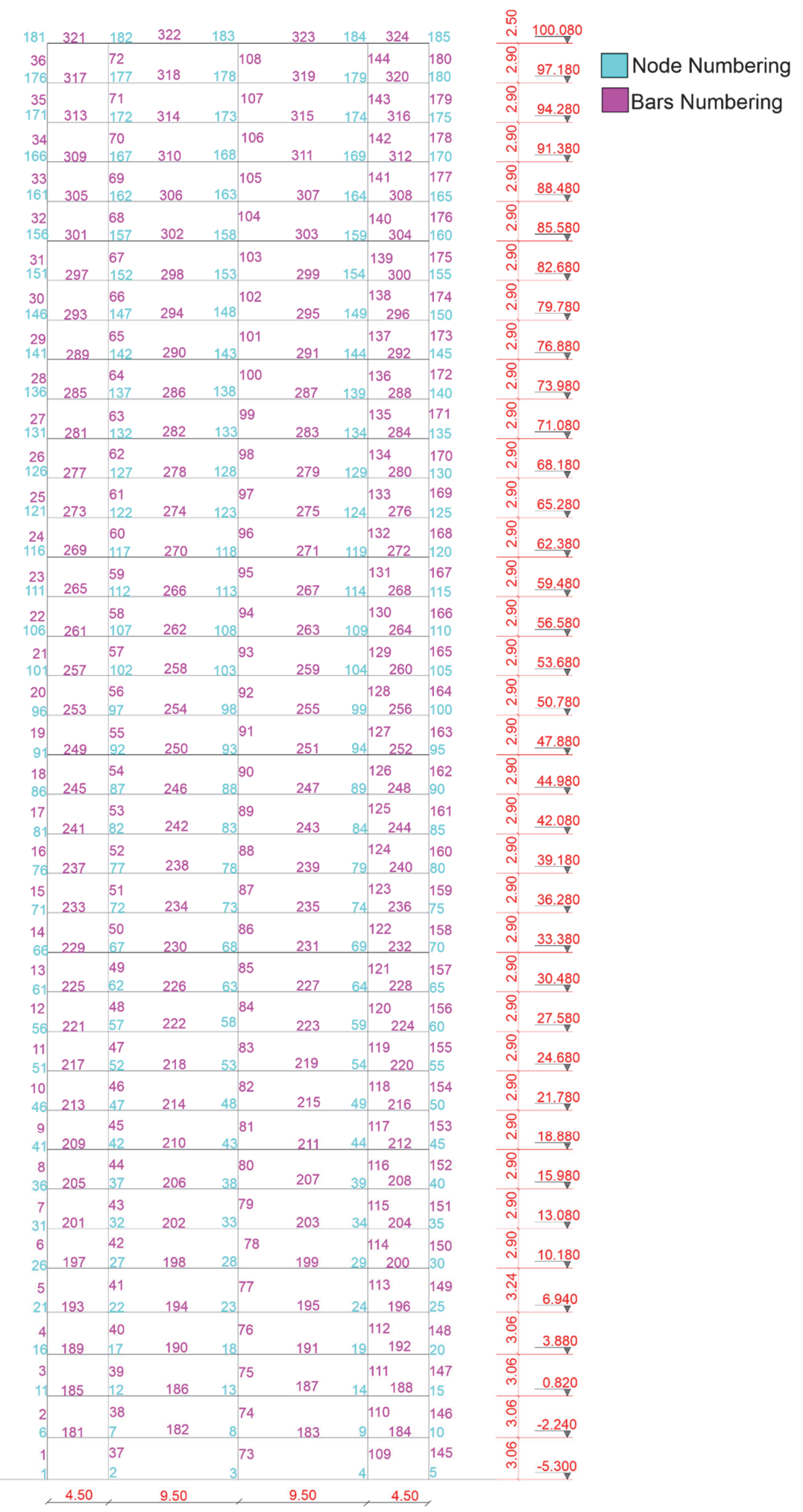

Figure 3: structure studied in this paper 
The factor $S_{1}$ is the topographic factor that takes into account variations in terrain relief. It has a value of 1 for slightly rough terrain. $S_{3}$ is a statistical factor based on the type of use of the building, with a value of 1 for the case studied, residential building. The factor $S_{2}$ considers the combined effect of the terrain roughness, the variation in wind speed with the height above the terrain and the dimensions of the building or part of the building under consideration, being calculated according to Eqn. 10, with the help of Tab. 1 of [21]:

$$
S_{2}=b F_{r}(z / 10)^{p}
$$

The floating component of the wind can be calculated according to the procedures of chapter 9 of [21] (Dynamic effects due to atmospheric turbulence). However, there are other procedures that, despite being more complex, are more efficient and better suited to different structures.

One of these procedures is the analysis using the spectral representation method. Considering the fluctuating wind speed as a normal random process with a mean of zero, it is possible to reach the fluctuating component of the wind from the superposition of harmonic waves [22] by Eqn. 11:

$$
\Delta \vec{V}(t)=\sum_{j=1}^{N} \sqrt{2 S_{W}\left(f_{j}\right) \Delta f_{j}} \cos \left(2 \pi f_{j} t+\phi_{j}\right)
$$

where $\phi_{j}$ is a random variable with a uniform probability distribution defined between 0 and $2 \pi$. $\Delta f_{j}$ is obtained by $f_{j+1}-f_{j}$, that is, from the division of the frequency range of interest.

The calculation of the power spectral density is given by the model proposed by Harris (Eqn. 12):

$$
\frac{f S_{w}(f)}{u_{*}^{2}}=\frac{4 n}{\left(2+n^{2}\right)^{5 / 6}}
$$

where:

$$
\begin{aligned}
& n=\frac{f_{S_{W}} L}{V_{0}} \\
& u_{*}=0.4 \frac{\overrightarrow{V_{z_{r f}}}}{\ln \left(\frac{\tau_{r e f}}{\tau_{0}}\right)}
\end{aligned}
$$

where $\mathrm{V}_{0}$ is the reference speed at a height of 10 meters where the structure is located, $\mathrm{f}_{\mathrm{sw}}$ is the frequency band used in the spectrum, $\mathrm{u}^{*}$ is the wind flow cutoff speed and $\mathrm{z}_{0}$ is the roughness length, which is related to the height of the obstacles making up the roughness of the surface, it can be roughly estimated as one-twentieth of the average height of the obstacles. The roughness length is a parameter sensitive to changes in dimensions and density of obstacles; and, therefore, it is recommended to pay attention to the values obtained, and the use of small values favors security [23].

After calculating the velocities, the next step is calculating the correlation length. The length of vertical correlation between two points will be calculated according to the expression given by [24]. The studied structure will be inserted in the correlation plane, and the velocity for each node of the structure will be obtained through linear interpolation. The results are shown in Figs. 4 and 5.

From the length of correlation, the fluctuating velocities at all nodes of the structure were obtained and then the vector of applied forces in time for each node of the structure was obtained. Once the force vector is calculated, the dynamic response itself is started (displacements, velocities and accelerations) through the Newmark Integration Method, using a time step $d t$ $=0.1 \mathrm{~s}$ and 999 integration points. From the analysis, an average maximum displacement at the top of approximately $0.38 \mathrm{~m}$ was obtained, for situations where there is no energy dissipator. This value is considered high for design situations. 


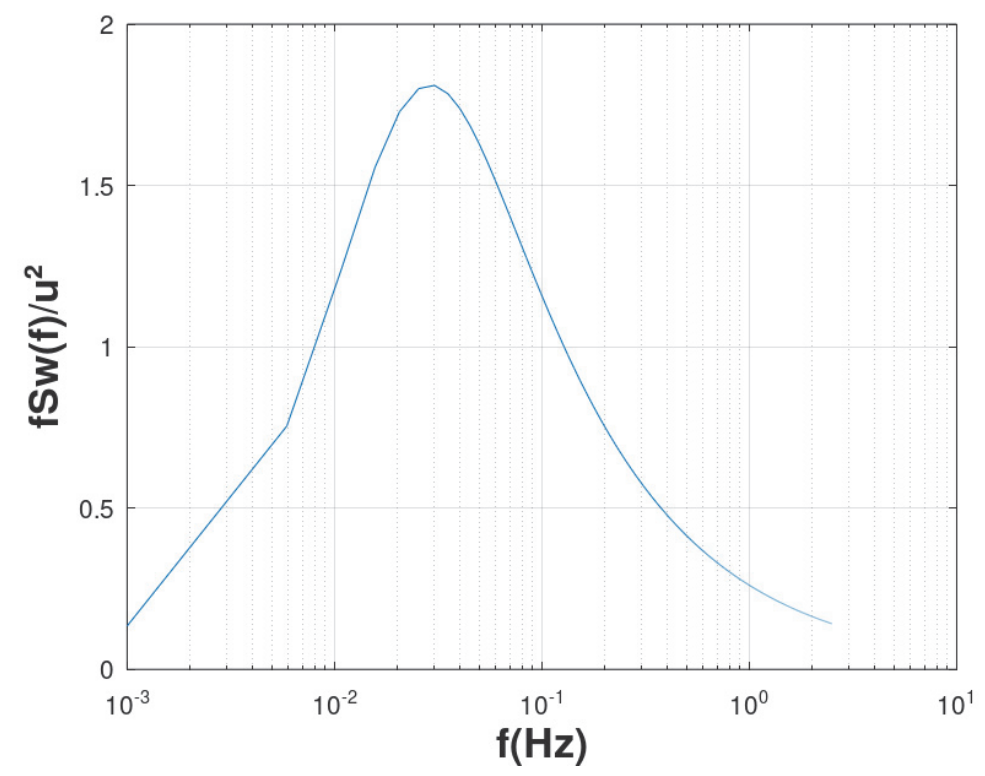

Figure 4: Harris power spectrum

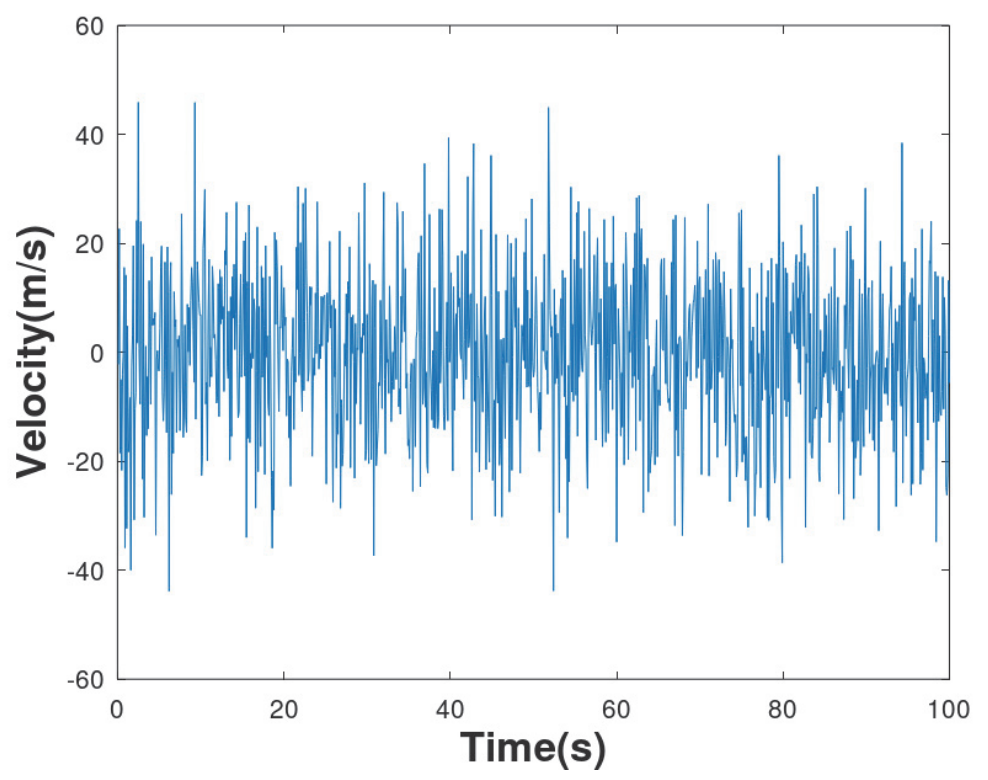

Figure 5: Floating longitudinal component in EPS wind

The Whale Optimization Algorithm (WOA)

Optimization algorithms have been undergoing a constant evolution process, and this process includes metaheuristic algorithms.

The Whale Optimization Algorithm (WOA) is a metaheuristic algorithm that is based on the hunting behavior of humpback whales. In general, humpback whales hunt prey through the formation of bubbles while directing them through spiral movements.

As with other evolutionary algorithms, WOA starts its search process through the random generation of an initial population of candidates (whales) delimited by the design space defined by the user of the technique. The new population is formed from the previous population and new candidates generated from three operators. Once the population is created, the optimal solution is given as the best candidate of this population, generating a new population around the optimal value. This procedure is repeated until a defined stopping criterion, usually the number of repetitions of this procedure, which is 
defined by the programmer before the simulations. The pseudo-code of WOA is shown in Fig. 6 and according to [24] the following input parameters are necessary: $\mathrm{D}_{\mathrm{im}}$ (number of design variables); fobj (objective function); $\mathrm{N}_{\mathrm{sa}}$ (number of search agents, that is, the whale population); Ngen (maximum number of generations, that is, maximum iteration number); Lb (lower bound, where $\mathrm{Lbn}_{\mathrm{b}}$ the lower bound of variable $\mathrm{n}$, for example: $\mathrm{Lb}_{\mathrm{b}}=[\mathrm{Lb} 1, \mathrm{Lb2}, \ldots ., \mathrm{Lbn}]$ ); $\mathrm{Ub}_{\mathrm{b}}$ (upper bound, where Ubn the upper bound of variable $\mathrm{n}$, for example: $\left.\mathrm{U}_{\mathrm{b}}=\left[\mathrm{U}_{\mathrm{b} 1}, \mathrm{U}_{\mathrm{b} 2}, \ldots, \mathrm{U}_{\mathrm{bn}}\right]\right)$. Fig. 7 shows the parameters which must be updated, where a is decreased from 2 to 0 in order to provide exploration and exploitation, respectively; A and C, are coefficients utilized to calculate the best current solution; 1 , is a random number in $[-1,1]$; and $\mathrm{p}$, is a random number in $[0,1][25]$.

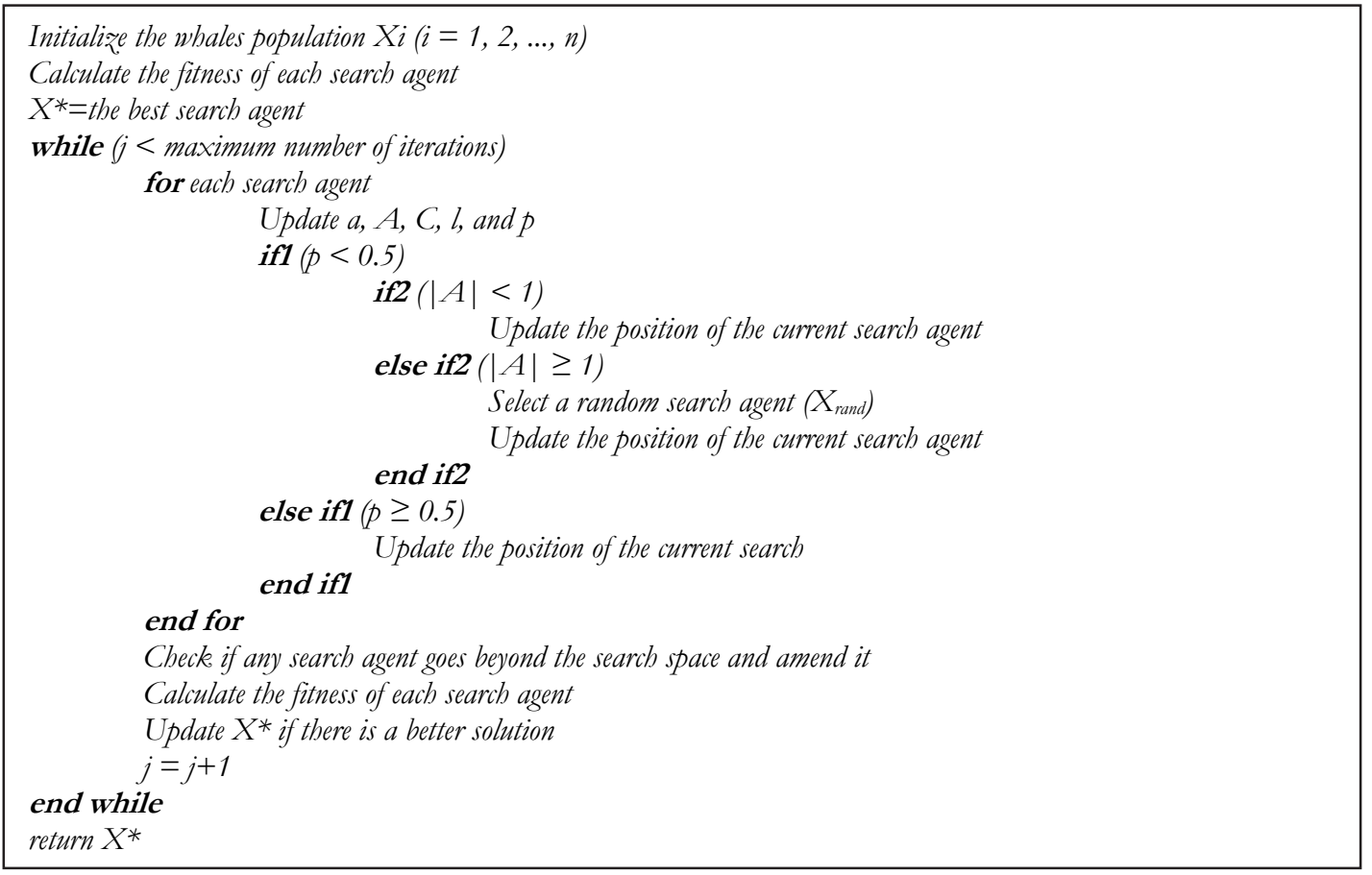

Figure 6: Pseudo-code of the WOA [25].

\section{Formulation of the dynamic ptimization problem}

Faced with high displacement values, it is essential to resize the structure so that it respects the maximum displacement values according to appropriate codes and standards, whether national or international. In this work, we chose to use as a basis the American standard ASCE/SEI 7-10 [26], which according to its appendix C, comments that the maximum displacement value of a structure is calculated as $\mathrm{d}_{\text {Máx }}=\mathrm{H} / 400$, where $\mathrm{H}$ is the total height of the building. Therefore, for this problem, the maximum displacement constraint is approximately $0.26 \mathrm{~m}$. In addition to the maximum displacement at the top of the structure, there are also restrictions on relative displacements between floors (story drift). According to the American standard, the story drift of each floor cannot exceed $10 \mathrm{~mm}$ (approximately $3 / 8$ of an inch).

The design variables are the heights of the cross-sections of the beams and columns (Fig. 7), keeping the base values fixed. In addition to member heights, the damping and stiffness values of each TMD are also inserted as design variables in the optimization problem. The lateral limits are in Tab. 3:

\begin{tabular}{ccc}
\hline Design variables & Lower bound & Upper bound \\
$\mathrm{x} 1 / \mathrm{x} 3 / \mathrm{x} 5 / \mathrm{x} 7 / \mathrm{x} 9(\mathrm{~cm})$ & 80 & 120 \\
$\mathrm{x} 2 / \mathrm{x} 4 / \mathrm{x} 6 / \mathrm{x} 8 / \mathrm{x} 10(\mathrm{~cm})$ & 20 & 80 \\
x11 to x46 $(\mathrm{cm})$ & 12 & 100 \\
TMD's stiffness $(\mathrm{N} / \mathrm{m})$ & 0 & $1.955 \mathrm{e} 4$ \\
TMD's damping & 0 & 391.08 \\
\hline
\end{tabular}

Table 3: Lateral limits of design variables 


\begin{tabular}{|c|c|c|c|c|c|c|}
\hline & & $x 46$ & & x46 & & \\
\hline$x 2$ & $x 4$ & $x 45$ & x6 & x45 & x8 & $\times 10$ \\
\hline$x 2$ & $\mathrm{x} 4$ & x44 & $x 6$ & x44 & x8 & $\times 10$ \\
\hline$x 2$ & $x 4$ & $x 43$ & $x 6$ & x43 & $x 8$ & $\times 10$ \\
\hline$x 2$ & $x 4$ & $x 42$ & x6 & $x 42$ & $x 8$ & $\times 10$ \\
\hline$\times 2$ & $x 4$ & $x 41$ & $x 6$ & x41 & $x 8$ & $\times 10$ \\
\hline$x 2$ & $x 4$ & $x 40$ & $x 6$ & $x 40$ & $x 8$ & $\times 10$ \\
\hline$x 2$ & $x 4$ & x39 & x6 & x39 & $x 8$ & $\times 10$ \\
\hline$x 2$ & $x 4$ & x38 & x6 & x38 & $x 8$ & $x 10$ \\
\hline$x 2$ & $x 4$ & x37 & $x 6$ & x37 & $x 8$ & $\times 10$ \\
\hline$x 2$ & $x 4$ & x36 & x6 & x36 & x8 & $x 10$ \\
\hline$x 2$ & $x 4$ & x35 & x6 & x35 & $x 8$ & $\times 10$ \\
\hline$x 2$ & $x 4$ & x34 & $x 6$ & x34 & $x 8$ & $x 10$ \\
\hline$x 2$ & $x 4$ & x33 & $x 6$ & x33 & x8 & $\times 10$ \\
\hline$x 2$ & $x 4$ & x32 & $x 6$ & x32 & $x 8$ & $\times 10$ \\
\hline$x 2$ & $x 4$ & $\times 31$ & x6 & x31 & x8 & $x 10$ \\
\hline$x 2$ & $x 4$ & x30 & $x 6$ & x30 & $x 8$ & $\times 10$ \\
\hline$x 2$ & $x 4$ & $\times 29$ & x6 & $x 29$ & $x 8$ & $x 10$ \\
\hline$x 2$ & $x 4$ & $\times 28$ & $x 6$ & $x 28$ & $x 8$ & $x 10$ \\
\hline$\times 1$ & $x 3$ & $\times 27$ & $\times 5$ & $\mathrm{x} 27$ & $x 7$ & $\times 9$ \\
\hline$x 1$ & $x 3$ & $x 26$ & $x 5$ & $x 26$ & $x 7$ & $\times 9$ \\
\hline$x 1$ & $x 3$ & $\times 25$ & $x 5$ & $\times 25$ & $x 7$ & $\times 9$ \\
\hline$x 1$ & $x 3$ & $x 24$ & x5 & $x 24$ & $x 7$ & x9 \\
\hline$x 1$ & $x 3$ & $x 23$ & $x 5$ & $x 23$ & $x 7$ & $\times 9$ \\
\hline$\times 1$ & $x 3$ & $\times 22$ & $\times 5$ & $x 22$ & $x 7$ & $\times 9$ \\
\hline$\times 1$ & $x 3$ & $x 21$ & $x 5$ & $x 21$ & $x 7$ & x9 \\
\hline$\times 1$ & $x 3$ & $x 20$ & $x 5$ & $\times 20$ & $x 7$ & $\times 9$ \\
\hline$x 1$ & $x 3$ & $\mathrm{x} 19$ & $\times 5$ & $x 19$ & $x 7$ & $\times 9$ \\
\hline$x 1$ & $x 3$ & x18 & $x 5$ & $x 18$ & $x 7$ & $\times 9$ \\
\hline$\times 1$ & x3 & $x 17$ & x5 & $\mathrm{x} 17$ & $x 7$ & $\times 9$ \\
\hline$\times 1$ & $\times 3$ & $\mathrm{x} 16$ & x5 & x16 & $x 7$ & $\times 9$ \\
\hline $\mathrm{x} 1$ & $x 3$ & $x 15$ & $\times 5$ & $\mathrm{x} 15$ & $x 7$ & $\times 9$ \\
\hline$x 1$ & $\times 3$ & $\times 14$ & $\times 5$ & $\mathrm{x} 14$ & $x 7$ & $\times 9$ \\
\hline$x 1$ & $x 3$ & $x 13$ & x5 & $\mathrm{x} 13$ & $x 7$ & $\times 9$ \\
\hline$x 1$ & $x 3$ & $x 12$ & x5 & $\mathrm{x} 12$ & $x 7$ & x9 \\
\hline $\mathrm{x} 1$ & x3 & $x 11$ & x5 & $\mathrm{x} 11$ & $x 7$ & x9 \\
\hline$\times 1$ & $x 3$ & & $x 5$ & & $x 7$ & $\times 9$ \\
\hline
\end{tabular}

Figure 7: Design variables of the optimization problem. 
The objective function consists in the minimization of the volume of the concrete of the structure, calculated as:

$$
V_{\text {structure }}=\sum_{i=1}^{n_{\text {bars }}} L_{i} A_{i}
$$

where $\mathrm{L}$ and $\mathrm{A}$ are the lengths and area of each member, respectively. Therefore, the optimization problem is formulated as follows:

Find: $X_{i}=\left(b_{i}\right)$ where $i=1,2, \ldots, 46$

Find: $T_{i}=\left(k_{i}, c_{i}\right)$ where $i=1,2, \ldots, N_{\text {AMS }}$

Minimize $V_{\text {struture }}=\sum_{i=1}^{n_{\text {bur }}} L_{i} A_{i}$

Subject to $d_{M a x} \leq 0.26 m$ e $\Delta_{b}=v_{i}-v_{i-1} \leq 10 \mathrm{~mm}$

Once the optimization problem was defined, 4 scenarios to control the structure were proposed, seeking the best performance of the structure with the smallest possible volume of concrete:

Scenario 1: Optimization of the structure, without the presence of TMD;

Scenario 2: Optimization with a TMD on top of the building;

Scenario 3: Optimization with two TMDs on top of the building; and

Scenario 4: Optimization with two TMD's, one on top of the building and one on the next floor (penultimate floor).

\begin{tabular}{ccc}
\hline Model & Concrete Volume $\left(\mathrm{m}^{3}\right)$ & Average Volume $\left(\mathrm{m}^{3}\right)$ \\
Original & 260.72 & 260.72 \\
Otim. 1 & 226.14 & \\
Otim. 2 & 219.22 & \\
Otim. 3 & 232.26 & \\
Otim. 4 & 230.61 & \\
Otim. 5 & 229.10 & \\
Otim. 6 & 217.98 & \\
Otim. 7 & 225.39 & \\
Otim. 8 & 215.72 & \\
Otim. 9 & 213.49 & \\
Otim. 10 & 223.75 & \\
\hline
\end{tabular}

Table 4: Comparison between concrete volume values from scenario 1 simulations.

\section{RESULTS AND DISCUSSIONS}

\section{Scenario 1}

he first scenario consists of optimizing the structure from the height of the cross-sections of the bars, without the presence of TMD, under dynamic excitation due to the wind. For this, the WOA optimization algorithm is used.

30 research agents and 900 iterations were used. Due to the probabilistic nature of the optimization algorithm, 10 independent simulations were performed and the results averaged. The number of iterations needed was evaluated using the iteration curve versus concrete volume (Fig. 8), noting that from iteration 4 or 5 , the convergence of the value already occurs. However, the 30 iterations are used to ensure that all simulations are at the optimal value.

10 simulations were performed and the average of the results was calculated, where values are listed in Tab. 4. It is noticed that from the optimization process it was possible to reduce the volume of concrete in the original structure by approximately $14.33 \%$. To verify whether the optimization algorithm was respecting the design maximum displacement 
constraints, the heights of the bars given by the algorithm in one of the simulations were used, and the dynamic analysis was performed again, comparing the optimized top displacement with the displacement in the top without optimization. The results are shown in Fig. 9.

It is important to emphasize that in addition to having managed to bring the building to a maximum displacement value within the acceptable limit in the standard (it reduced from $0.38 \mathrm{~m}$ to $0.24 \mathrm{~m}$ ), the concrete volume of the structure was also reduced.

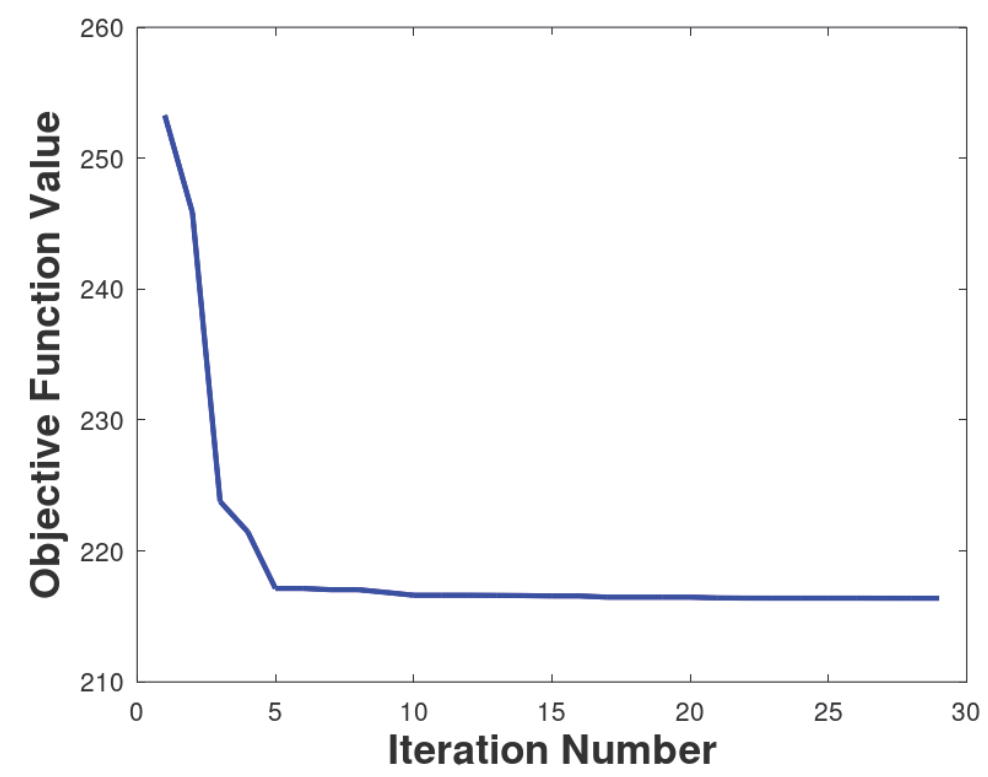

Figure 8: Convergence curve of Scenario 1.

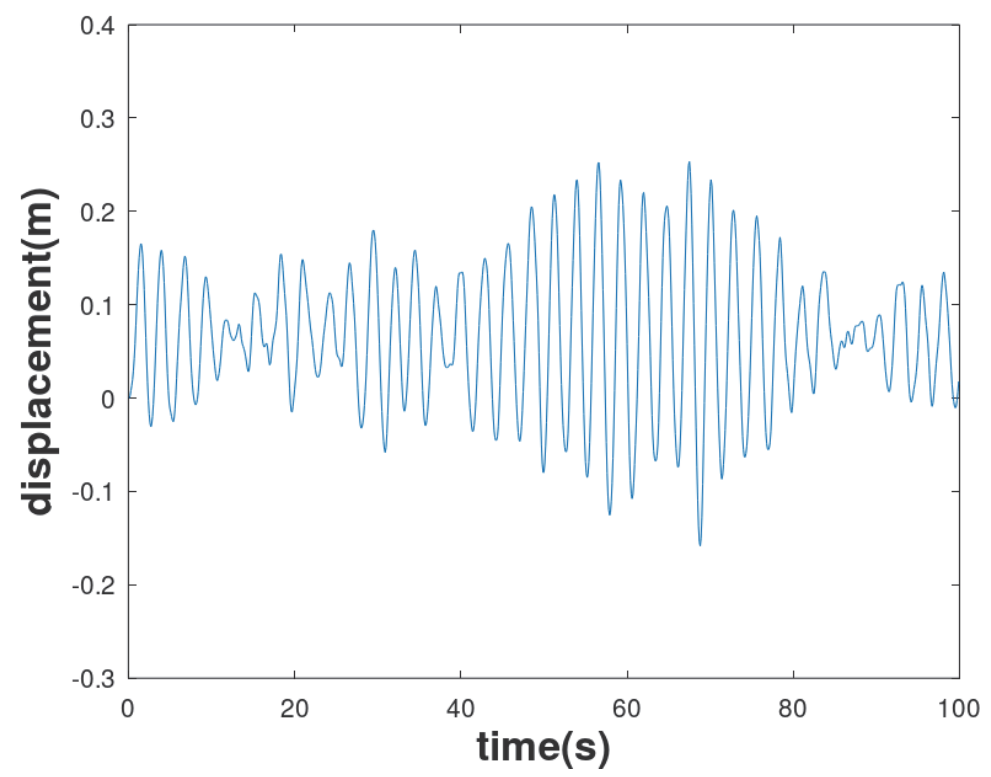

Figure 9: Displacement on top of optimized structure

Scenario 2

In this scenario, a TMD was inserted at the top of the structure, connected to node 183 of the structural model. This scenario presents the classic vibration control solution with TMD, by adding one more DOF to the structure. The definition of the location of the energy dissipator is due to the fact that the building's first vibration mode generates greater movements on higher floors. Different from scenario 1, scenario 2 has two more design variables, which are TMD stiffness and damping. All other considerations are identical to scenario 1. The TMD's mass was adopted as $3 \%$ of the structure mass as 
recommended in the bibliography, resulting in about 20 tons. The results are shown in Tab. 5. As in the previous case, the number of iterations was evaluated through the convergence of the optimal response to the problems, and it is clear that from the 12th iteration on, the result has already been stabilized.

It is noticed that the simulation with TMD reached values approximately $11 \%$ smaller in concrete volume than the simulation of scenario 1, and approximately $23.59 \%$ smaller than the original volume of the structure, respecting the maximum values of displacement at the top and displacement relative between floors (story drift).

This behavior is based on the existing literature, showing that the insertion of TMD at the top of buildings, with its appropriate optimized parameters, reduces the amplitude of displacements due to the dynamic excitation of the wind, and thus, the volume of structure without exceeding the normative displacement limit.

The average TMD properties calculated by the algorithm are mentioned in Tab. 6 .

\begin{tabular}{ccc} 
Model & Concrete Volume $\left(\mathrm{m}^{3}\right)$ & Average Volume $\left(\mathrm{m}^{3}\right)$ \\
Original & 260.72 & 260.72 \\
Otim. 1 & 187.88 \\
Otim. 2 & 187.36 \\
Otim. 3 & 201.16 \\
Otim. 4 & 205.38 \\
Otim. 5 & 212.44 \\
Otim. 6 & 199.11 \\
Otim. 7 & 201.5 \\
Otim. 8 & 206.42 \\
Otim. 9 & 203.4 \\
Otim. 10 & 189.1 \\
\hline
\end{tabular}

Table 5: Comparison between concrete volume values from scenario 2 simulations.

\begin{tabular}{cc}
\hline Parameters & Average Value \\
Stiffness $(\mathrm{N} / \mathrm{m})$ & 8315.12 \\
Damping $(\mathrm{Ns} / \mathrm{m})$ & 97.93 \\
\hline
\end{tabular}

Table 6: TMD parameters obtained by optimization

\section{Scenario 3}

In scenario 3, two TMDs were inserted into the structure, equivalent to scenario 2, on the top floor of the building, at nodes 182 and 184. The optimal dissipator's design is performed for the mass ratio defined in scenario 2 , that is, a total mass of $3 \%(1.5 \%$ for each of the 2 TMD). That is, the resulting value of approximately 20 tons is divided equally between each TMD considered in each current analysis. WOA parameters remained the same as in the previous scenario for all analyzes performed in this third scenario. As in the previous case, the number of iterations was evaluated through the convergence of the optimal answer to the problems, and it is possible to verify that convergence was reached in the 13 th iteration, but it is important to perform all iterations. The concrete volume values obtained in the simulations are shown in Tab. 7 .

It can be seen from the results in the table that the average value of concrete volume of the optimization process is slightly higher than the average value of the previous scenario, with a single TMD at the top (approximately 4\%). However, this 
optimization allowed a reduction in the volume of concrete of $20.48 \%$ compared to the original structure, a good reduction in construction. The stiffness and damping values of the TMDs are in Tab. 8.

There is a considerable difference between the characteristics of the two TMDs. Installing devices with different properties can be difficult or more costly compared to a solution that has the same specifications for each TMD, so for this simulation, the scenario with only one TMD on top becomes more efficient.

\begin{tabular}{ccc}
\hline Model & Concrete Volume $\left(\mathrm{m}^{3}\right)$ & Average Volume $\left(\mathrm{m}^{3}\right)$ \\
Original & 260.72 & 260.72 \\
Otim. 1 & 187.88 & \\
Otim. 2 & 187.36 & 201.16 \\
Otim. 3 & 205.38 \\
Otim. 4 & 212.44 & \\
Otim. 5 & 199.11 & \\
Otim. 6 & 201.5 \\
Otim. 7 & 206.42 \\
Otim. 8 & 203.4 \\
Otim. 9 & 189.1 \\
\hline Otim. 10
\end{tabular}

Table 7: Comparison between concrete volume values from scenario 3 simulations.

\begin{tabular}{cc}
\hline Parameters & Average Value \\
Stiffness of TMD 1 (N/m) & 13798.07 \\
Damping of TMD 1 (Ns/m) & 210.92 \\
Stiffness of TMD 2 (N/m) & 5418.04 \\
Damping of TMD 2 (Ns/m) & 169.61 \\
\hline
\end{tabular}

Table 8: TMDs parameters obtained by optimization

\section{Scenario 4}

In the last scenario, two TMDs were inserted in the structure, one on the top floor and another on the penultimate one, located at nodes 183 and 178. Again, the optimal dissipator's design is performed for the mass ratio defined in scenario 2, with a value of $3 \%$, this mass being divided equally between the two TMDs. WOA parameters remained the same as in the previous scenario for all analyzes performed in this fourth scenario. As in the previous case, the number of iterations was evaluated through the convergence of the optimal answer to the problems, being possible to verify that the convergence was reached in the 25th iteration. The convergence curve was analyzed in all simulations carried out in this research in order to guarantee the optimal design for each situation. The concrete volume values obtained in the simulations are shown in Tab. 9.

From the table, it can be seen that the concrete volume results are very similar to the results of scenario 3 , which also uses 2 TMD, with a difference of only $2 \%$ in the average volumes. Consequently, there was a reduction in concrete volume in relation to the original system of approximately $19.8 \%$, an interesting value for the engineering practice. The stiffness and damping values of the TMD's are in Tab. 10. 


\begin{tabular}{ccc} 
Model & Concrete Volume $\left(\mathrm{m}^{3}\right)$ & Average Volume $\left(\mathrm{m}^{3}\right)$ \\
Original & 260.72 & 260.72 \\
Otim. 1 & 214.63 & \\
Otim. 2 & 202.25 \\
Otim. 3 & 213.93 \\
Otim. 4 & 204.63 \\
Otim. 5 & 202.3 \\
Otim. 6 & 205.62 \\
Otim. 7 & 210.13 \\
Otim. 8 & 216.94 \\
Otim. 9 & 201.78 \\
Otim. 10 & \\
\hline
\end{tabular}

Table 9: Comparison between concrete volume values from scenario 4 simulations.

\begin{tabular}{cc}
\hline Parameters & Average Value \\
Stiffness of TMD 1 $(\mathrm{N} / \mathrm{m})$ & 10008.48 \\
Damping of TMD 1 $(\mathrm{Ns} / \mathrm{m})$ & 191.52 \\
Stiffness of TMD 2 $(\mathrm{N} / \mathrm{m})$ & 5052.47 \\
Damping of TMD 2 $(\mathrm{Ns} / \mathrm{m})$ & 190.18 \\
\hline
\end{tabular}

Table 10: TMDs parameters obtained by optimization

\begin{tabular}{ccccc}
\hline Simulation & Without TMD & 1 TMD & 2 TMD's (One Floor) & 2 TMD's (Two Floors) \\
\hline 1 & 226.14 & 187.88 & 192.63 & 201.78 \\
2 & 219.22 & 187.36 & 214.17 & 214.63 \\
3 & 232.26 & 201.16 & 201.96 & 219.86 \\
4 & 230.61 & 205.38 & 199.67 & 202.25 \\
5 & 229.1 & 212.44 & 207.76 & 213.93 \\
6 & 217.98 & 199.11 & 216.62 & 204.63 \\
7 & 225.39 & 201.5 & 202.3 & 202.3 \\
8 & 215.72 & 206.42 & 214.37 & 205.62 \\
9 & 213.49 & 203.4 & 203.4 & 210.13 \\
10 & 223.75 & 189.1 & 205.6 & 209.94 \\
Average & 223.37 & 199.38 & 205.85 & 19.76 \\
Initial Volume: & 260.72 & & & 20.48 \\
Difference (\%) & 14.33 & 23.53 & & \\
\hline
\end{tabular}

Table 11: Overall results of optimization processes 
Again, there is a considerable difference between the stiffness values of the two TMDs. However, the damping values are very close, an interesting point for installing the attenuators. It should be noted that, for all simulations performed with TMDs, all restrictions on displacement between floors (story drift) and maximum displacement at the top were respected. Among the 3 scenarios with the presence of TMD's, this scenario was the one with the highest average volume value, and scenario 1 with the lowest concrete volume values. In a way, scenario 1 was expected to be the best scenario, since the solution with 1 TMD on top is a classic solution and widely used by researchers. A summary of all results is shown in Tab. 11.

\section{ConClusions}

I $\mathrm{n}$ this work, procedures for the optimization of a concrete building through a metaheuristic algorithm were presented, from a 2D frame structure of 42 floors, totaling approximately 105 meters high and 4 spans of beams, susceptible to vibrations caused by wind. Computational routines for dynamic analysis and simulation of wind force were created (comprising the action of atmospheric turbulence in the wind direction and without considering neighborhood effects), as well as a routine to obtain the dynamic response from the method of integration of Newmark. These routines were developed in Octave language and integrated with the WOA optimization algorithm. Several simulations were performed, and in all of them, smaller values of concrete volume were obtained in relation to the initial structure, which shows the effectiveness of the method proposed in this work.

Given the simulations carried out in this work and the results obtained, it is clear that the procedure proposed in this paper to optimize concrete structures through metaheuristic algorithms is satisfactory, bringing good results in relation to the volume of concrete (reduction of up to $24 \%$ in relation to original structure), and also in relation to the maximum displacement required by the standard, respecting the limit value. That is, the original project, in addition to having a larger concrete volume, did not respect the maximum displacement requirements of standards, however, after the proposed optimizations, in all scenarios, the concrete volume was reduced and the structure began to respect the code limits.

Regarding the insertion of TMDs, all insertion scenarios are positive and reduced the volume of concrete in a greater quantity than the optimization without TMD. The greater efficiency of scenario 2 is highlighted, which is the type of control most commonly found in the literature to reduce building displacement amplitude. Scenarios 3 and 4 are also efficient, despite the different parameters of each attenuator, which can make the TMD installation process more expensive.

\section{ACKNOWLEDGMENTS}

he authors acknowledge the financial support of CNPq and CAPES, Brazil.

\section{REFERENCES}

[1] Thornton, C.H., Joseph, L., Scarangello, T. (1990). Optimization of tall structures for wind loading, J. Wind Eng. Ind. Aerodyn., 36(1-3), pp. 235-244, DOI: 10.1016/0167-6105(90)90308-Y.

[2] Venanzi, I., Materazzi, A.L. (2007). Multi-objective optimization of wind-excited structures, Eng. Struct., 29(6), pp. 983990, DOI: $10.1016 /$ j.engstruct.2006.07.007.

[3] Yang, J.N., Agrawal, A.K., Samali, B., Wu, J.C. (2004). A benchmark problem for response control of wind-excited tall buildings, Proc. Int. Modal Anal. Conf. - IMAC, 1(April), pp. 151-157, DOI: $10.1061 /$ (asce)0733-9399(2004)130:4(437).

[4] Miguel, L.F.F., Miguel, L.F.F. (2012). Novel metaheuristic algorithms applied to optimization of structures, WSEAS Trans. Appl. Theor. Mech., 7(3), pp. 210-220.

[5] Miguel, L.F.F., Miguel, L.F.F. (2013). Assessment of modern metaheuristic algorithms - HS, ABC and FA - in shape and size optimisation of structures with different types of constraints, Int. J. Metaheuristics, 2(3), pp. 256, DOI: 10.1504/ijmheur.2013.056404.

[6] Holland, J.H. (1992). Adaptation in Natural and Artificial Systems: An Introductory Analysis with Applications to Biology, Control, and Artificial Intelligence, DOI: 10.7551/mitpress/1090.001.0001. 
[7] Lei, Z., Gao, S., Gupta, S., Cheng, J., Yang, G. (2020). An aggregative learning gravitational search algorithm with selfadaptive gravitational constants, Expert Syst. Appl., 152, pp. 113396, DOI: 10.1016/j.eswa.2020.113396.

[8] Yang, X.S. (2009). Harmony search as a metaheuristic algorithm, Stud. Comput. Intell., 191, pp. 1-14, DOI: 10.1007/978-3-642-00185-7_1.

[9] Marini, F., Walczak, B. (2015). Particle swarm optimization (PSO). A tutorial, Chemom. Intell. Lab. Syst., 149, pp. 153165, DOI: 10.1016/j.chemolab.2015.08.020.

[10] Dorigo, M., Birattari, M., Stutzle, T. (2006). Ant colony optimization, IEEE Comput. Intell. Mag., 1(4), pp. 28-39, DOI: 10.1109/MCI.2006.329691.

[11] Mirjalili, S., Lewis, A. (2016). The Whale Optimization Algorithm, Adv. Eng. Softw., 95, pp. 51-67, DOI: $10.1016 /$ j.advengsoft.2016.01.008.

[12] Longarini, N., Cabras, L., Zucca, M., Chapain, S., Aly, A.M. (2017). Structural Improvements for Tall Buildings under Wind Loads: Comparative Study, Shock Vib., DOI: 10.1155/2017/2031248.

[13] Saaed, T.E., Nikolakopoulos, G., Jonasson, J.E., Hedlund, H. (2015). A state-of-the-art review of structural control systems, JVC/Journal Vib. Control, 21(5), pp. 919-937, DOI: 10.1177/1077546313478294.

[14] Symans, M.D., Constantinou, M.C. (1999). Semi-active control systems for seismic protection of structures: A state-ofthe-art review, Eng. Struct., 21(6), pp. 469-487, DOI: 10.1016/S0141-0296(97)00225-3.

[15] Varela, W.D., Battista, R.C. (2011). Control of vibrations induced by people walking on large span composite floor decks, Eng. Struct., 33(9), pp. 2485-1494, DOI: 10.1016/j.engstruct.2011.04.021.

[16] Rossato, B.B., Miguel, L.F.F. (2019). Optimization of parameters of tuned mass dampers for use in tall buildings subjected to the wind action, XL CILAMCE Ibero-Latin Am. Congr. Comput. Methods Eng., pp. 12.

[17] Liu, Y., Wang, K., Mercan, O., Chen, H., Tan, P. (2020). Experimental and numerical studies on the optimal design of tuned mass dampers for vibration control of high-rise structures, Eng. Struct., 211, pp. 110486, DOI: $10.1016 /$ j.engstruct.2020.110486.

[18] Den Hartog, J.P. (1956). Mechanical Vibrations, New York: McGraw-Hill.

[19] Warburton, G.B. (1982). Optimum absorber parameters for various combinations of response and excitation parameters, Earthq. Eng. Struct. Dyn., 10(3), pp. 381-401, DOI: 10.1002/eqe.4290100304.

[20] ABNT. (2014). ABNT NBR 6118:2014 - Projeto de estruturas de concreto, Proj. Estruturas Concreto, Procedimento. Norma Bras., pp. 238.

[21] Associação Brasileira de Normas Técnicas. (1988). Forças devidas ao vento em edificações: NBR 6123, Rio de Janeiro.

[22] Shinozuka, M., Jan, C.M. (1972). Digital simulation of random processes and its applications, J. Sound Vib., 25(1), pp. 111-128, DOI: 10.1016/0022-460X(72)90600-1.

[23] Blessmann, J. (2013). O Vento na Engenharia Estrutural, Porto Alegre: Editora UFRGS.

[24] Miguel, L.F.F., Fadel Miguel, L.F., Riera, J.D., Kaminski, J., Ramos de Menezes, R.C. (2012). Assessment of code recommendations through simulation of EPS wind loads along a segment of a transmission line, Eng. Struct., 43, pp. 1-11, DOI: 10.1016/j.engstruct.2012.05.004.

[25] Brandão, F. da S., Miguel, L.F.F. (2020). Vibration control in buildings under seismic excitation using optimized tuned mass dampers, Frat. Ed Integrita Strutt., 14(54), pp. 66-87, DOI: 10.3221/IGF-ESIS.54.05.

[26] American Society od Civil Engineers. (2010). Minimum Design Loads for Buildings and Other Structures: ASCE/SEI 7-10, Reston, Virginia. 